\title{
SHORT COMMUNICATION \\ THE PRESENCE OF MULTIDRUG-RESISTANT \\ STAPHYLOCOCCAL ISOLATES OUTSIDE \\ OF A MAJOR HOSPITAL IN LONDON, UNITED \\ KINGDOM
}

\author{
Adi Idris ${ }^{1,2}$, Ron R. Cutler ${ }^{3}$ \\ 1PAPRSB Institute of Health Sciences, Brunei Darussalam University, Brunei Darussalam \\ ${ }^{2}$ Menzies Institute of Health Queensland, School of Medical Science, Griffith University, Southport, Australia \\ ${ }^{3}$ School of Biological and Chemical Sciences, Queen Mary University of London, London, United Kingdom
}

\section{SUMMARY}

Objective: Drug-resistant staphylococci have been a growing threat to the community and hospitals due to the misuse of antibiotics by humans, industrialisation and lack of novel antimicrobials currently available. Little is known about the prevalence of drug-resistant staphylococci in nonhealthcare environments outside hospitals in the London area. Staphylococci can spread via contact with contaminated objects. Traffic light buttons present a fast and easy transmission route for staphylococci.

Methods: Traffic light buttons outside a major hospital in London were swabbed and cultured onto selective media to isolate staphylococci bacteria before performing antimicrobial susceptibility testing on the isolates. The identity of the isolates were determined using MALDI-TOF mass spectrometry (MS). Staphylococci isolates resistant to oxacillin were further tested for minimum inhibitory concentration (MIC). PCR analysis of the mecA gene, a gene that confers resistance to oxacillin, is used to determine the level of resistance to oxacillin.

Results: Eight different staphylococcal species were identified by MALDI-TOF-MS analysis. Out of the 66 staphylococci isolates, 16 were resistant to multiple antibiotics including six isolates which were oxacillin resistant.

Conclusion: This work provides evidence of the presence of multidrug-resistant staphylococci in the vicinity of the hospital environment in London.

Key words: staphylococci, MALDI, non-hospital, antibiotic resistance, environment

Address for correspondence: A. Idris, Menzies Institute of Health Queensland, School of Medical Science, Griffith University, Southport, 4222, Queensland, Australia. E-mail: a.idris@griffith.edu.au

https://doi.org/10.21101/cejph.a5000

\section{INTRODUCTION}

Staphylococcus aureus and coagulase-negative staphylococci (CoNS) are major contaminants of touch surfaces; they are pervasive in both clinical and non-clinical surfaces (1). The transmission of staphylococci, including methicillin-resistant strains, occurs primarily via direct contact with these contaminated surfaces. The ability of staphylococci to survive for long periods of time on surfaces in public areas, where they frequently come into contact with people, can facilitate their easy transmission from person to person.

Staphylococci are recognized as a species of bacteria often closely related to human and animal hosts. The most well studied member of this genus is methicillin resistant Staphylococcus aureus (MRSA), a common hospital and environmental pathogen. It is now clear that there is a high number of Staphylococcus aureus and MRSA contaminations in non-hospital environments (2). There have only been a handful of studies investigating the incidence of multiple drug resistant staphylococci from non- healthcare environments including hotels (3), restroom surfaces $(4,5)$, public transport places $(6-10)$, water parks (11), public telephones (12), and fitness centres (13-15). Little is known about the prevalence of drug-resistant staphylococci in nonhealthcare environments outside hospitals in the London area. Staphylococci can spread via contact with contaminated objects. Traffic light buttons present a fast and easy transmission route for staphylococci. This study investigated the presence of multidrug resistant staphylococci on traffic lights in the vicinity of a major urban hospital in London.

\section{MATERIALS AND METHODS}

\section{Sample Collection}

Dry sterile cotton swabs (Copan Diagnostics Inc, CA) were used to collect samples from various traffic lights in the vicinity of a major hospital in London. Approximately $4 \mathrm{~cm}^{2}$ areas were 
sampled using dry cotton swabs which were stored in sterile swab collection tubes. A total of 40 surface samples were collected from several traffic light buttons along the main road adjacent to the hospital, in areas within a 0.75 -mile (mi) radius of the hospital on a dry June 2016 summer day (daytime temperature $\sim 27^{\circ} \mathrm{C}$ ). All specimens were transferred to the laboratory within 1-3 hours of the sample being taken.

\section{Culture and Primary Bacteria Isolation}

In the laboratory, the swabs were plated onto Nutrient Agar (Nutrient Agar, Oxoid, Basingstoke, UK) medium before swabbing on Mannitol Salt Agar (MSA, Oxoid, Basingstoke, UK) selective medium to select for Gram-positive cocci. Plates were incubated for up to $48 \mathrm{~h}$ at $37^{\circ} \mathrm{C}$. Bacterial colonies growing on MSA are then subcultured onto another MSA plate to ensure purity of the colonies.

\section{Preparation of Bacterial Isolates for MALDI-TOF- MS Analysis}

Colonies (3-5) of overnight cultures were suspended in 300 $\mu 1$ distilled water. The suspension was mixed with $100 \%$ absolute ethanol and centrifuged for $1 \mathrm{~min}$ at $13,000 \mathrm{x}$ g. The pellets were resuspended in $25 \mu \mathrm{l}$ of $70 \%$ formic acid and then $25 \mu \mathrm{l}$ pure acetonitrile was added. After mixing, solutions were centrifuged at $13,000 \mathrm{xg}$ for $2 \mathrm{~min}$. One $\mathrm{ml}$ aliquots of the supernatant were spotted in duplicate onto MALDI ground steel targets, air-dried for $5 \mathrm{~min}$ at room temperature and each target spot was then overlaid with $1 \mu$ la-cyano-4-hydroxycinnamic (HCCA) matrix solution.

\section{Identification of Bacterial Isolates Using MALDI- TOF-MS}

All isolates were purified and analysed by matrix-assisted laser desorption/ionization time of flight mass spectrometry (MALDITOF-MS) (Microflex LT, MALDI-TOF-MS, Bruker Daltonics, Coventry, UK) in a positive linear mode $(2,000$ to $20,000 \mathrm{~m} / \mathrm{z}$ range). The resulting spectra for each culture was analysed by MALDI-Biotyper 2.0 software (Bruker Daltonics, Coventry, UK). The software evaluates each spectrum compared to reference spectra in the Bruker Taxonomy Database identifying the best match from database records. Results were expressed as scores (QI) from 0 to 3, as recommended by the manufacturer. Scores $\mathrm{QI} \leq 1.7$ were not considered as reliable identification. A score of $\mathrm{QI} \geq 1.7$ corresponded to 'genus' identification. Only scores higher than $\mathrm{QI} \geq 2$ were considered a reliable identification of species.

\section{Antimicrobial Susceptibility Testing}

Strains were screened for resistance to antibiotics by agar disk diffusion on Iso Sensitest media (Iso Sensitest Agar, Oxoid, Basingstoke, UK). Zones of inhibition were evaluated against twelve antibiotic (Oxoid, Basingstoke, UK). The following antibiotic discs were used: chloramphenicol (30 g), erythromycin (15 g), fusidic acid (10 g), oxacillin (1 g), penicillin G (1 unit), streptomycin $(10 \mathrm{~g})$, tetracycline $(10 \mathrm{~g})$, cefoxitin $(30 \mathrm{~g})$, gentamicin (10 g), vancomycin (5 g), cefepime (30 g), and mupirocin (20 g). The minimum inhibitory concentrations (MICs) to oxacillin were additionally evaluated using "MIC evaluators", antimicrobial gradient strips designed for accurate minimum inhibitory concentration values (Oxoid Ltd., Basingstoke, UK). The categories susceptible, intermediate resistant or resistant were assigned on the basis of the Clinical and Laboratory Standards Institute (CLSI) antimicrobial susceptibility testing standards.

\section{RESULTS}

Eighty-two out of the 92 environmental isolates (89.1\%) were identified using MALDI-TOF-MS (Table 1). The remaining 10 isolates $(10.9 \%)$ failed to give a reliable identification. The rates of MALDI-TOF identification at the species level with a score of $\mathrm{QI} \geq 2$ were $87.8 \%(72 / 82)$ and at genus level with a score of $1.7 \leq \mathrm{QI} \leq 2$ were $12.5 \%(10 / 80)$. In this study, a large number of staphylococci were recovered from our environmental samples. Overall, we identified 66 staphylococcal isolates belonging to 8 species. This included Staphylococcus simiae $(\mathrm{n}=10)$, Staphylococcus warneri $(\mathrm{n}=7)$, Staphylococcus auricularis $(\mathrm{n}=2)$, Staphylococcus hominis $(\mathrm{n}=4)$, Staphylococcus pettenkoferi $(\mathrm{n}=1)$, Staphylococcus capitis $(\mathrm{n}=10)$, Staphylococcus epidermidis $(\mathrm{n}=24)$, and Staphylococcus pasteuri $(\mathrm{n}=8)$. We also identified several other bacteria such as bacillus, micrococcus, corynebacterium, kocuria, and aerococcus. Our findings highlight the complexity of the number of bacterial types that can be found on human contact surfaces in the non-hospital environment. Commensal skin bacteria, usually shed from human skin, such as Corynebacterium and staphylococci are commonly found in public places such as gyms (13) and restrooms (16). Results of this study indicate that a wide range of bacterial species was isolated from the non-hospital environment but staphylococci were the most common. In light of these findings, these non-hospital isolates of staphylococci were selected to assess their antibiotic resistance profiles.

\section{DISCUSSION}

Most of the staphylococci isolated in our study carried antibiotic determinants. Staphylococci were isolated from traffic light buttons in the vicinity of the hospital. 57 out of our 66 staphylococci isolates $(86.4 \%)$ had antibiotic resistance, including resistance to non- $\beta$ lactam antibiotics such as fusidic acid, chloramphenicol, vancomycin and erythromycin (Table 2). The isolated staphylococci isolates were also resistant to other antibiot-

Table 1. Summary of family and genera of bacteria identified by MALDI-TOF-MS $(N=82)$

\begin{tabular}{|l|l|c|}
\hline Family & Genus & Isolates (n) \\
\hline Staphylococcaceae & Staphylococcus & 66 \\
\hline Bacillaceae & Bacillus & 3 \\
\hline Micrococcaceae & Micrococcus & 9 \\
\hline Micrococcaceae & Kocuria & 1 \\
\hline Corynebacteriaceae & Corynebacterium & 1 \\
\hline Aerococcaceae & Aerococcus & 2 \\
\hline Total & & 82 \\
\hline
\end{tabular}


ics such as gentamicin, ciprofloxacin, streptomycin and tetracycline. Four of the isolates were resistant to five or more antibiotics (\#4, \#19, \#31 and \#43) of which two isolates were resistant to oxacillin (\#4 and \#43) (Table 2). No apparent trend between the distance from the hospital and the number of antibiotics that the staphylococci isolates were resistant to could be seen from our preliminary study. The limited number of samples in our current dataset does not permit us to conduct a proper statistical analysis to assess this trend. Methicillin resistance is commonly associated with the carriage of the mecA gene, which encodes the penicillin binding protein PBP2a. Our results also showed that three of the staphylococci environmental isolates were resistant to oxacillin with varying minimum inhibitory concentrations (MIC) (Table 2).

\section{CONCLUSION}

The presence of antibiotic resistance found in staphylococci samples collected from traffic lights outside of a major hospital in the London area indicates that some environments may accelerate the spread of antibiotic resistant strains. To our knowledge, this is the first attempt to investigate the presence of multidrug resistant staphylococci on traffic light surfaces, let alone in the vicinity of a major hospital. Attention should be paid to the inspection and control of antibiotic resistant strains in these environments as these isolates could be transferred into the nearby hospital environment. This further highlights that public environments are potential 'breeding

Table 2. Resistance profiles and molecular characterization of antibiotic resistant staphylococci isolated from traffic light buttons around a major hospital in London, United Kingdom

\begin{tabular}{|c|c|c|c|c|c|c|c|c|c|c|c|c|c|c|c|c|c|c|}
\hline$\#$ & Species & L & $\mathrm{n}$ & 0 & $\mathrm{Cf}$ & $\mathbf{P}$ & V & M & $C p$ & G & Fc & $S$ & A & $E$ & $T$ & C & $\begin{array}{c}0 \\
\text { E-test } \\
\text { MIC }\end{array}$ & $\begin{array}{c}0 \\
\text { Micro } \\
\text { MIC }\end{array}$ \\
\hline 1 & S. hominis & $0 \mathrm{mi}$ & 1 & & & & & & & & $\mathrm{R}$ & & & & & & & \\
\hline 2 & S. epidermidis & $0 \mathrm{mi}$ & 1 & & & $\mathrm{R}$ & & & & & $\mathrm{R}$ & & $\mathrm{R}$ & $\mathrm{R}$ & & & & \\
\hline 3 & S. warneri & $0 \mathrm{mi}$ & 1 & & & $\mathrm{R}$ & & & & & $\mathrm{R}$ & & $\mathrm{R}$ & & & & & \\
\hline 4 & S. pasteuri & $0 \mathrm{mi}$ & 1 & $\mathrm{R}$ & $\mathrm{R}$ & $\mathrm{R}$ & & $\mathrm{R}$ & $\mathrm{R}$ & & $\mathrm{R}$ & & $\mathrm{R}$ & $\mathrm{R}$ & & & 48 & 32 \\
\hline 5 & S. pasteuri & $0 \mathrm{mi}$ & 1 & & $\mathrm{R}$ & $\mathrm{R}$ & & & & & $\mathrm{R}$ & & & & & & & \\
\hline 6 & S. simiae & $0 \mathrm{mi}$ & 1 & & & & $\mathrm{R}$ & & & & & & & & & & & \\
\hline 7 & S. simiae & $0 \mathrm{mi}$ & 1 & & & & $R$ & & & & $\mathrm{R}$ & & & & & & & \\
\hline 8 & S. simiae & $0 \mathrm{mi}$ & 4 & & & & & & & & & & & & & & & \\
\hline 9 & S. simiae & $0 \mathrm{mi}$ & 3 & & & & & & & & $\mathrm{R}$ & & & & & & & \\
\hline 10 & S. simiae & $0 \mathrm{mi}$ & 1 & & & $\mathrm{R}$ & $\mathrm{R}$ & & & & & & & & & & & \\
\hline 11 & S. hominis & $0 \mathrm{mi}$ & 1 & & & $\mathrm{R}$ & & & & & & & & & & & & \\
\hline 12 & S. captis & $0 \mathrm{mi}$ & 1 & & & $\mathrm{R}$ & & & & & $\mathrm{R}$ & & & & & & & \\
\hline 13 & S. epidermidis & $0 \mathrm{mi}$ & 1 & & & & $\mathrm{R}$ & & & & & & & $\mathrm{R}$ & & & & \\
\hline 14 & S. captis & $0 \mathrm{mi}$ & 2 & & & $\mathrm{R}$ & & & & & $\mathrm{R}$ & & & & & & & \\
\hline 15 & S. epidermidis & $0 \mathrm{mi}$ & 1 & & & & & & & & $\mathrm{R}$ & & & & & & & \\
\hline 16 & S. epidermidis & $0 \mathrm{mi}$ & 2 & & & & & & & & & & & $\mathrm{R}$ & & & & \\
\hline 17 & S. warneri & $0 \mathrm{mi}$ & 1 & & & & & & & & $\mathrm{R}$ & & $\mathrm{R}$ & & & & & \\
\hline 18 & S. warneri & $0 \mathrm{mi}$ & 1 & & & & & & & & & & & & & & & \\
\hline 19 & S. epidermidis & $0.25 \mathrm{mi}$ & 1 & & & $\mathrm{R}$ & $\mathrm{R}$ & & & & $\mathrm{R}$ & & $\mathrm{R}$ & $\mathrm{R}$ & & & & \\
\hline 20 & S. warneri & $0.25 \mathrm{mi}$ & 1 & & & & & & & $\mathrm{R}$ & $\mathrm{R}$ & & & & & & & \\
\hline 21 & S. epidermidis & $0.25 \mathrm{mi}$ & 1 & & & & & $\mathrm{R}$ & & & & & & & & & & \\
\hline 22 & S. captis & $0.25 \mathrm{mi}$ & 1 & & & & & & & & & & & & & & & \\
\hline 23 & S. captis & $0.25 \mathrm{mi}$ & 2 & & & & & & & & $\mathrm{R}$ & & & & & & & \\
\hline 24 & S. epidermidis & $0.25 \mathrm{mi}$ & 1 & & & $\mathrm{R}$ & & & & & & & & & & & & \\
\hline 25 & S. epidermidis & $0.25 \mathrm{mi}$ & 1 & & & $\mathrm{R}$ & $\mathrm{R}$ & & & & $\mathrm{R}$ & & $\mathrm{R}$ & & & & & \\
\hline 26 & S. warneri & $0.5 \mathrm{mi}$ & 1 & & & $\mathrm{R}$ & & & & & $\mathrm{R}$ & & $\mathrm{R}$ & $\mathrm{R}$ & & & & \\
\hline 27 & S. epidermidis & $0.5 \mathrm{mi}$ & 6 & & & & & & & & $\mathrm{R}$ & & & & & & & \\
\hline 28 & S. epidermidis & $0.5 \mathrm{mi}$ & 1 & & & & & & & & & & & $\mathrm{R}$ & & & & \\
\hline 29 & S. pasteuri & $0.5 \mathrm{mi}$ & 1 & & & $\mathrm{R}$ & & & & & $\mathrm{R}$ & & $\mathrm{R}$ & $\mathrm{R}$ & & & & \\
\hline 30 & S. captis & $0.5 \mathrm{mi}$ & 1 & & $\mathrm{R}$ & $\mathrm{R}$ & & & & & $\mathrm{R}$ & & & & & & & \\
\hline 31 & S. epidermidis & $0.5 \mathrm{mi}$ & 1 & & $\mathrm{R}$ & & $\mathrm{R}$ & $R$ & & & $\mathrm{R}$ & & & $\mathrm{R}$ & & & & \\
\hline
\end{tabular}

Continued on the next page 
Continued from the previous page

Table 2. Resistance profiles and molecular characterization of antibiotic resistant staphylococci isolated from traffic light buttons around a major hospital in London, United Kingdom

\begin{tabular}{|c|c|c|c|c|c|c|c|c|c|c|c|c|c|c|c|c|c|c|}
\hline$\#$ & Species & L & $\mathrm{n}$ & 0 & Cf & $\mathbf{P}$ & V & M & $C p$ & G & Fc & $S$ & A & $\mathbf{E}$ & $\mathrm{T}$ & C & $\begin{array}{c}0 \\
\text { E-test } \\
\text { MIC }\end{array}$ & $\begin{array}{c}0 \\
\text { Micro } \\
\text { MIC }\end{array}$ \\
\hline 32 & S. epidermidis & $0.5 \mathrm{mi}$ & 2 & & & $\mathrm{R}$ & & & & & $\mathrm{R}$ & & $\mathrm{R}$ & $\mathrm{R}$ & & & & \\
\hline 33 & S. epidermidis & $0.5 \mathrm{mi}$ & 1 & & & & & & & & $\mathrm{R}$ & & & $\mathrm{R}$ & & & & \\
\hline 34 & S. captis & $0.5 \mathrm{mi}$ & 1 & & & & & $\mathrm{R}$ & & & & & & & & & & \\
\hline 35 & S. epidermidis & $0.5 \mathrm{mi}$ & 1 & & & & $\mathrm{R}$ & & & & $\mathrm{R}$ & & & & & & & \\
\hline 36 & S. epidermidis & $0.5 \mathrm{mi}$ & 1 & & & $\mathrm{R}$ & & & & & & & $\mathrm{R}$ & $\mathrm{R}$ & & & & \\
\hline 37 & S. warneri & $0.5 \mathrm{mi}$ & 1 & & & $\mathrm{R}$ & & & & & $\mathrm{R}$ & & $\mathrm{R}$ & & & & & \\
\hline 38 & S. pasteuri & $0.5 \mathrm{mi}$ & 1 & & & $\mathrm{R}$ & & & & & $\mathrm{R}$ & & & $\mathrm{R}$ & & & & \\
\hline 39 & S. pasteuri & $0.5 \mathrm{mi}$ & 1 & & & & & & & & & & & & & & & \\
\hline 40 & S. auricularis & $0.5 \mathrm{mi}$ & 1 & & & & & & & & & & & & & & & \\
\hline 41 & S. warneri & $0.5 \mathrm{mi}$ & 1 & $\mathrm{R}$ & $\mathrm{R}$ & & & & & & & & & & & & 64 & 32 \\
\hline 42 & S. pasteuri & $0.5 \mathrm{mi}$ & 3 & & & $\mathrm{R}$ & & & & & & & $\mathrm{R}$ & & & & & \\
\hline 43 & S. auricularis & $0.5 \mathrm{mi}$ & 1 & $\mathrm{R}$ & $\mathrm{R}$ & $\mathrm{R}$ & $\mathrm{R}$ & & $\mathrm{R}$ & & $\mathrm{R}$ & & $\mathrm{R}$ & & & & 64 & 64 \\
\hline 44 & S. epidermidis & $0.5 \mathrm{mi}$ & 1 & & & $\mathrm{R}$ & & & & & & & & $\mathrm{R}$ & & & & \\
\hline 45 & S. hominis & $0.75 \mathrm{mi}$ & 1 & & & $\mathrm{R}$ & & & & & & & & & & & & \\
\hline 46 & S. pettenkoferi & $0.75 \mathrm{mi}$ & 1 & & & $\mathrm{R}$ & & & & & & & $\mathrm{R}$ & & & & & \\
\hline 47 & S. epidermidis & $0.75 \mathrm{mi}$ & 1 & & & $\mathrm{R}$ & & & & & & & & & & & & \\
\hline 48 & S. captis & $0.75 \mathrm{mi}$ & 1 & & & & & $\mathrm{R}$ & & & $\mathrm{R}$ & & & & & & & \\
\hline 49 & S. captis & $0.75 \mathrm{mi}$ & 1 & & & & & & & & & & & & & & & \\
\hline 50 & S. hominis & $0.75 \mathrm{mi}$ & 1 & & & & & & & & & & & & & & & \\
\hline
\end{tabular}

\# - assigned numerical code; $\mathrm{L}$ - location code 0, 0.25, 0.5, $0.75 \mathrm{mi} ; \mathrm{n}$ - similar isolates from each sampling location; O - oxacillin; Cf - ciprofloxacin; $\mathrm{P}$ - penicillin G; $\mathrm{V}$ - vancomycin; M - mupirocin; Cp - cefepime; G - gentamicin; Fc - fusidic acid; S - streptomycin; A - amoxicillin; E - erythromycin; T - tetracycline; C - chloramphenicol. O E-test MIC - minimum inhibitory concentration to oxacillin $(\mu \mathrm{g} / \mathrm{ml})$ based on Oxoid E-test strip.

O Micro MIC - minimum inhibitory concentration to oxacillin $(\mu \mathrm{g} / \mathrm{ml})$ based on broth microdilution assay.

grounds' for multidrug resistant staphylococci. The spread of multidrug resistance in such environments is evidence that infection control measures in hospitals and public places are ineffective in limiting the spread of such clones and that these environments are a source of antibiotic resistant pathogens. By knowing the type of drug resistant staphylococci circulating in the community we can devise measures to control their spread.

\section{Conflict of Interests}

None declared

\section{REFERENCES}

1. Kassem II. Chinks in the armor: the role of the nonclinical environmen in the transmission of Staphylococcus bacteria. Am J Infect Control. 2011;39(7):539-41.

2. Lin J, Lin D, Xu P, Zhang T, Ou Q, Bai C, et al. Non-hospital environment contamination with Staphylococcus aureus and methicillin-resistant Staphylococcus aureus: proportion meta-analysis and features of antibiotic resistance and molecular genetics. Environ Res. 2016;150:528-40.

3. Xu Z, Mkrtchyan HV, Cutler RR. Antibiotic resistance and mecA characterization of coagulase-negative staphylococci isolated from three hotels in London, UK. Front Microbiol. 2015;6:947. doi: 10.3389/ fmicb.2015.00947.
4. Gibbons SM, Schwartz T, Fouquier J, Mitchell M, Sangwan N, Gilbert JA, et al. Ecological succession and viability of human-associated microbiota on restroom surfaces. Appl Environ Microbiol. 2015;81(2):765-73.

5. Mkrtchyan HV, Xu Z, Cutler RR. Diversity of SCCmec elements in Staphylococci isolated from public washrooms. BMC Microbiol. 2015;15:120. doi: 10.1186/s12866-015-0451-3.

6. Zhou F, Wang Y. Characteristics of antibiotic resistance of airborne Staphylococcus isolated from metro stations. Int J Environ Res Public Health. 2013;10(6):2412-26.

7. Yeh PJ, Simon DM, Millar JA, Alexander HF, Franklin D. A diversity of antibiotic-resistant Staphylococcus spp. in a public transportation system. Osong Public Health Res Perspect. 2011;2(3):202-9.

8. Otter JA, French GL. Bacterial contamination on touch surfaces in the public transport system and in public areas of a hospital in London. Lett Appl Microbiol. 2009;49(6):803-5.

9. Simoes RR, Aires-de-Sousa M, Conceicao T, Antunes F, da Costa PM, de Lencastre H. High prevalence of EMRSA-15 in Portuguese public buses: a worrisome finding. PLoS One. 2011;6(3):e17630. doi: 10.1371/ journal.pone.0017630.

10. Stepanovic S, Cirkovic I, Djukic S, Vukovic D, Svabic-Vlahovic M Public transport as a reservoir of methicillin-resistant staphylococci. Lett Appl Microbiol. 2008;47(4):339-41.

11. Davis TL, Standridge JH, Degnan AJ. Bacteriological analysis of indoor and outdoor water parks in Wisconsin. J Water Health. 2009;7(3):452-63.

12. Jerković-Mujkić A, Bescaron R, Memiscaron S. Bacterial contamination of public telephones in the downtown area of Sarajevo. Afric J Microbiol Res. 2013;7(17):1664-7.

13. Mukherjee N, Dowd SE, Wise A, Kedia S, Vohra V, Banerjee P. Diversity of bacterial communities of fitness center surfaces in a U.S. metropolitan area. Int J Environ Res Public Health. 2014;11(12):12544-61. 
14. Markley JD, Edmond MB, Major Y, Bearman G, Stevens MP. Are gym surfaces reservoirs for Staphylococcus aureus? A point prevalence survey. Am J Infect Control. 2012;40(10):1008-9.

15. Ryan KA, Ifantides C, Bucciarelli C, Saliba H, Tuli S, Black E, et al. Are gymnasium equipment surfaces a source of staphylococcal infections in the community? Am J Infect Control. 2011;39(2):148-50.
16. Mkrtchyan HV, Russell CA, Wang N, Cutler RR. Could public restrooms be an environment for bacterial resistomes? PLoS One. 2013;8(1):e54223. doi: 10.1371/journal.pone.0054223.

Received December 7, 2016 Accepted in revised form June 30, 2019 